\title{
SIMULATION OF THE COMPACTION PROCESS OF A TWO-LEVEL POWDER METALLURGICAL PART
}

\author{
A. Bejarano, M. D. Riera, J. M. Prado \\ Centre Tecnològic de Manresa, Universitat Politècnica de Catalunya, Spain
}

\begin{abstract}
In this work, a Plasticity model for granular materials, based on the Drucker-Prager/CAP model, is applied to represent the behaviour of the metallic powders during their cold die compaction. The elastic deformation has been simulated by means of a non-linear law. These constitutive equations have been implemented in a commercial code to simulate the compaction and ejection processes of a two-level PM part.
\end{abstract}

KEYWORDS: POWDER METALLURGY, COMPACTION, MECHANICAL BEHAVIOUR OF GRANULAR MATERIALS, SIMULATION.

\section{INTRODUCTION}

In the Metalworking Industry the design and the control of the processes have been traditionally based on the experience and, sometimes, considered as an art; trial and error methods are still being very frequently applied, but they are inefficient technically and also economically. The application of numerical methods, as it is well known in these days, reduce the costs of the design and elaboration processes and, moreover, contributes to the improvement of the product quality. The main objective of the numerical simulation is to determine the best way to produce good-quality parts. Nevertheless, this technique requires the complete knowledge of the mechanics of the deformation developed during the process: the mechanical behaviour of the material and the influence of variables such as friction, geometry, tools, temperature, ...

In this work the authors present the simulation of the cold compaction of a two-level powder metallurgical part using the ABAQUS Finite Element code. The plastic behaviour of these metallic powders has been represented by means of the Drucker-Prager/CAP model, defined for geological materials. To simulate the ejection and, in general, the elastic strain, a pseudo-linear model of elasticity has been applied.

\section{THE MODEL}

The mechanical behaviour of metallic powders during their cold compaction is being represented by means of some models previously defined for geological materials. However, nowadays the aggregates of metallic particles are considered as frictional, nearly non-cohesive and granular materials.

\subsection{Plasticity}

Among different models of Plasticity, the Drucker-Prager/CAP one seems to be appropriate to represent the behaviour of the material, specially in the consolidation region. The authors of the present paper have some doubts about its effectiveness in representing its performance in states of failure [1]. But, there is not yet enough information to know all the features concerning the mechanical response of granular materials. Drucker and Prager [2] proposed a failure criterion that consists of a straight line, the failure line, the failure surface (Fig. 1), in the space of the first and second invariants of the stress and deviatoric stress tensors, $J_{1}$ and $J_{2 D}$, respectively. 


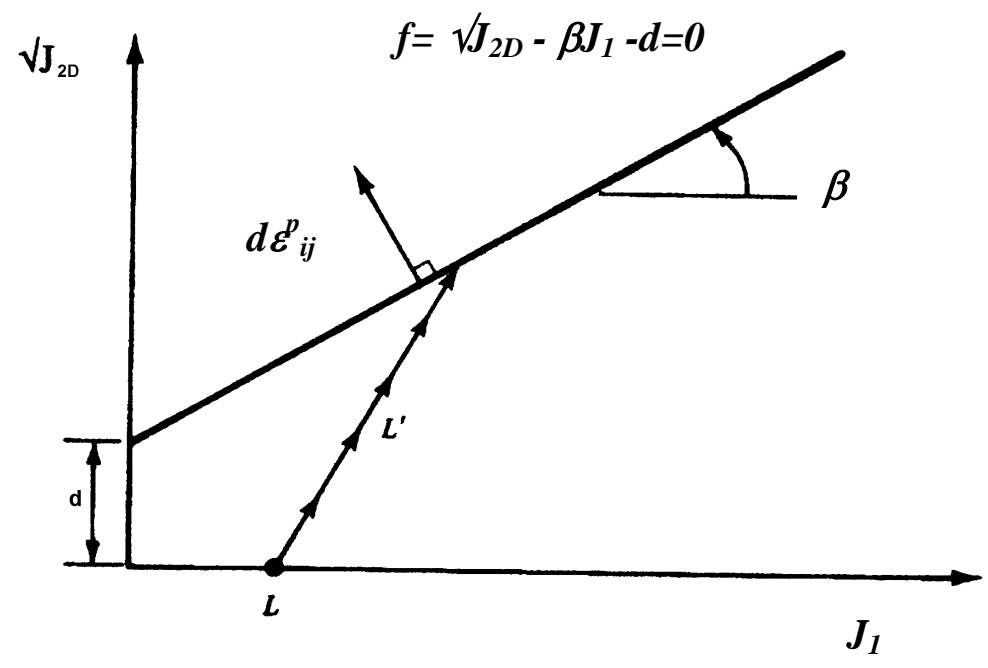

Figure 1: Drucker-Prager criterion. $d \varepsilon^{p}{ }_{i j}$ is an increment of the plastic strain and $d$ and $\beta$ are parameters of the material.

The line $L-L '$ corresponds to a loading path. After [3].
But, they realized that most of the materials that they were studying showed plastic strain from the first stages of the loading process; therefore, during the loading path $L-L^{\prime}$ in Fig. 1, the material is yielding continuously up to the failure, or ultimate state, which can be considered as the last yield surface; moreover, during the successive yielding the material hardens. This behaviour can be represented by means of a series of yield surfaces, the hardening caps, previous to the failure. This idea was first proposed by Drucker, Gibson and Henkel [4] and represented as it is shown in Fig. 2. For simplicity, these authors

supposed that the caps were of circular shape, but it depends on the material and it can be experimentally determined.

DiMaggio and Sandler proposed [5, 6] the CAP Plasticity model including elliptic caps and an exponential function representing the failure surface, as it is presented in Fig. 3.

This model consists of two yield surfaces regions: a pressure dependent exponential failure surface,

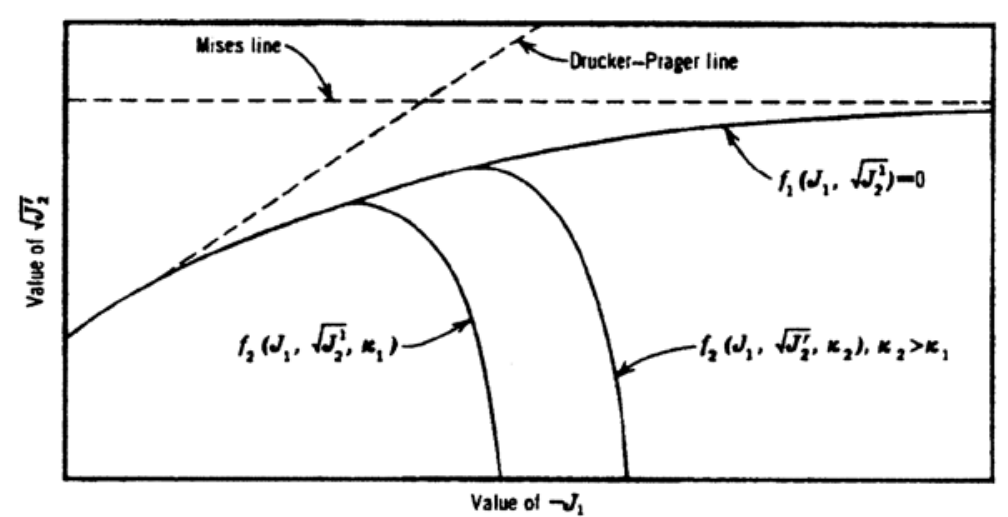

Figure 3: Caps and failure surface in the CAP Plasticity model, after [6]; $k$ is a hardening/softening parameter.

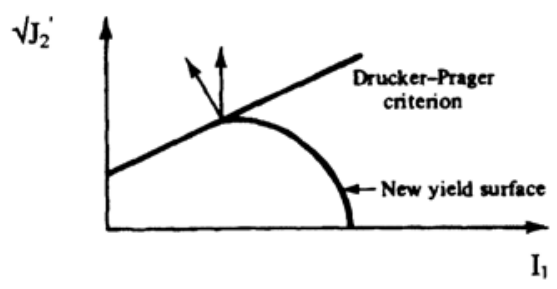

(a)

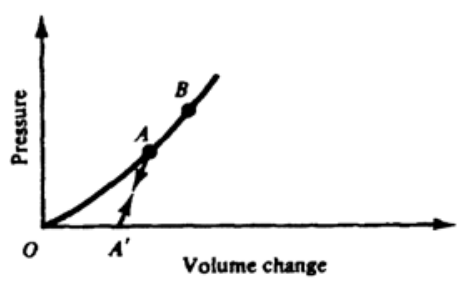

(b)

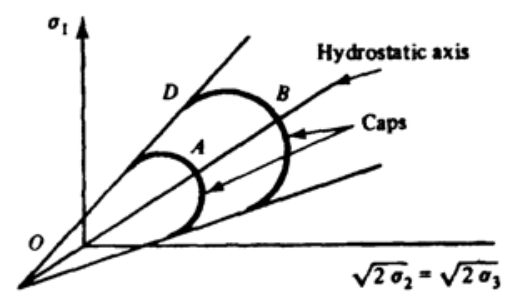

(c)

Figure 2: Mechanical behaviour of strain hardening granular materials, after [3].

$f_{1}\left(J_{1}, V_{2 D}\right)=0$, and an elliptic cap yield surface, $f_{2}\left(J_{1}, J_{2 D}, k\right)$. On the failure surface the material does not suffer mechanical strain hardening; the behaviour corresponds to a perfectly plastic material in the classical sense; but, the states of stress on this surface produce plastic, permanent, volumetric deformation.

But, some experimental results [1, $7,8,9]$ show that a Drucker-Prager failure surface together with the 
hardening caps of the type of those defined by DiMaggio and Sandler, would be a better way to model the behaviour of these materials. Then, this Drucker-Prager/CAP model, represented in Fig. 4 , is the one applied in this work, and implemented by means of the finite element code ABAQUS [10].

In terms of the deviatoric, $q$, and hydrostatic, $p$, stresses the equation describing the failure surface is:

$$
f_{1}=q-p \tan \beta-d=0
$$

where $\beta$ is the angle of friction, and $d$ represents the cohesion of the material.

The cap yield surface has an elliptic shape and is mathematically described by means of the following expression:

$$
f_{2}=\left[\left(p-p_{a}\right)^{2}+(R q)^{2}\right]^{1 / 2}-R\left(d+p_{a} \tan \beta\right)
$$

where $p_{a}$ is the hardening/softening parameter, related to the hydrostatic compression yield stress, $p_{b}$. $R$ is a material parameter controlling the eccentricity of the cap.

The model implemented here, as it can be seen in Fig. 4, has a transitional region between the two already described extreme surfaces, defined by means of a parameter $\alpha$ [10].

Plastic flow is associated on the cap, but non associated on the failure surface. Therefore, the flow potential surface is of

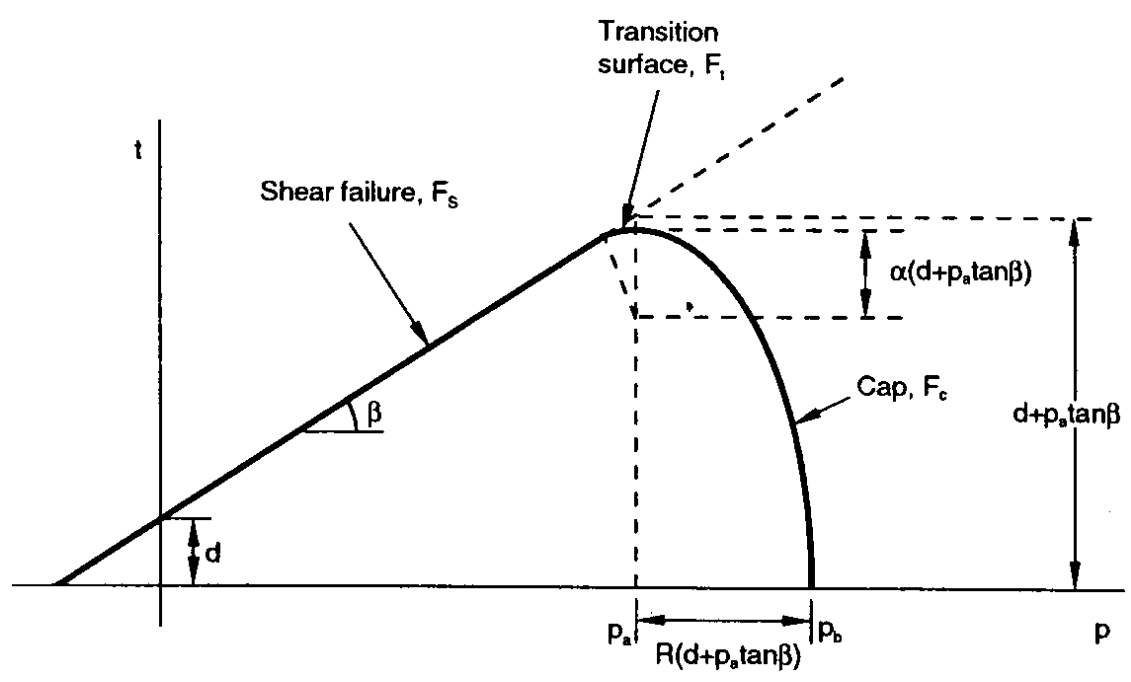

Figure 4: Yield surfaces for the Drucker-Prager/CAP model in the space of hydrostatic, $p$,-deviatoric, $q$, stresses, with the transition region implemented by ABAQUS [10]. the type shown in Fig. 5.

The part corresponding to the cap, $G_{c}$, is identical to the cap yield surface, $f_{2}$. But, it is necessary another elliptical portion in the failure and transition regions providing the non associated flow component in the model:

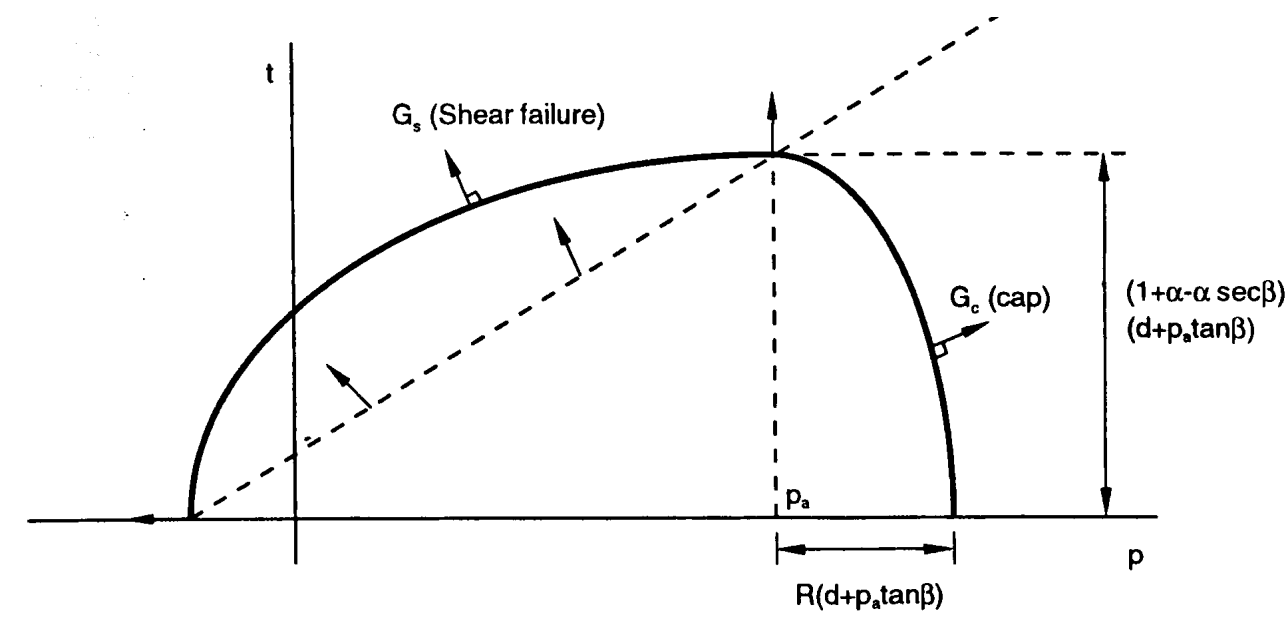

Figure 5: Flow potential in the Drucker-Prager/CAP model. 


$$
G_{s}=\left[\left(p-p_{a}\right)^{2}(\tan \beta)^{2}+(q)^{2}\right]^{1 / 2}
$$

$G_{s}$ and $G_{c}$ form a continuous and smooth potential surface. In these materials the mechanical response usually involves changes of volume; therefore, the hardening/softening behaviour is described by means of relating the mean stress and the volumetric strain (Fig. 6).

\subsection{Elasticity}

The elastic behaviour of metallic compacts is non linear [11, 12]. But, in this work the following density dependent law, proposed by [9], has been applied to represent the elasticity during the compaction and ejection of the material:

$$
E=K \exp \left(\rho / \rho_{o}\right)^{\alpha}
$$

where, $E$ is the Young's modulus of the material during its compaction; $\rho$ and $\rho_{o}$ are, respectively,

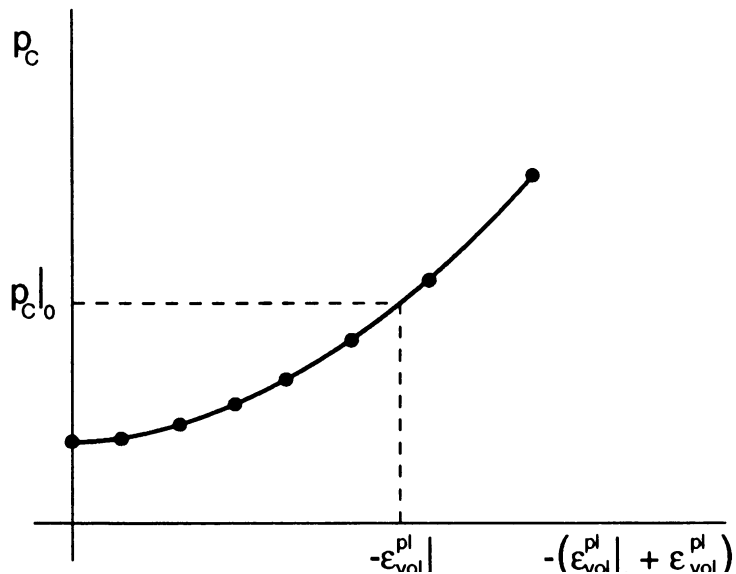

Figure 6: Typical law of hardening. the density and its initial value, and $K$ and $\alpha$ are parameters of the material which can be experimentally determined.

\section{SIMULATION}

\subsection{Parameters of the Material}

The material of interest in this work is a pre-alloyed, iron based and atomized powder, manufactured by Höganäs, the DISTALOY AE, which

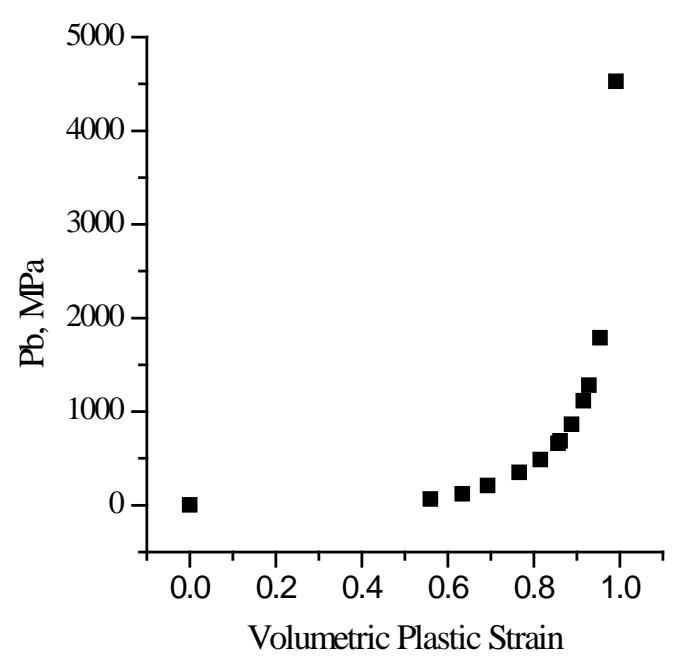

Figure 7: Hardening curve obtained from [9]. contains $4 \%$ of nickel, $1.5 \%$ copper, $0.5 \%$ molybdenum and $94 \%$ of iron. The material tested has been prepared by means of adding to this powder $1 \%$ of wax and $0.5 \%$ of graphite. The bulk density of this mixture is $7.33 \mathrm{Mg} / \mathrm{m}^{3}$.

To implement the model of Plasticity described in the previous section, 6 parameters concerning the yielding are needed: $d, \beta, R, p_{b}, p_{a}$ and $\alpha$. Their determination has not been specially done for this paper; they are provided by previous works. The cohesion strength, $d$, and the friction angle, $\beta$, the failure line parameters, were obtained by the authors from Brazilian [13] and uniaxial compression [7] tests. The cap eccentricity, $R$, experimentally tested by means of triaxial compression tests on cylindrical specimens, has been taken from [14]. The hydrostatic compression yield stress, $p_{b}$, for this material and, therefore, its hardening $p_{b}-\varepsilon^{p}{ }_{v}$, curve, were determined

by [9]. The hardening parameter, $p_{a}$, can be calculated from the following relationship:

$$
p_{a}=\frac{p_{b}-R d}{(1+R \tan \beta)}
$$


Finally, $\alpha$, is a small number (between 0.01 and 0.05 ) defined by the FEM code ABAQUS [9], used in this work as a tool of simulation. This parameter gives a smooth transition between the cap and failure surfaces.

The initial values introduced in the ABAQUS software have been: $d=3.254 \mathrm{MPa} ; \beta=70.84^{\circ} ; R=$ $0.68 ; p_{b}=4.144 \mathrm{MPa} ; p_{a}=0.653 \mathrm{MPa}$, and $\alpha=0.01$. The hardening curve is represented in Fig. 7.

The parameters for the elasticity, defined by means of the equation (3), are, following [9]: $K=8757$ MPa; $\alpha=5$. These data have been obtained from cyclic tests on samples.

\subsection{The Component and Tools}

The part object of this simulation is a bushing, pressed by Fax [15] and with the geometry drawn in Fig. 8.

In spite of being a common shape in the PM Industry, some problems can be derived due to

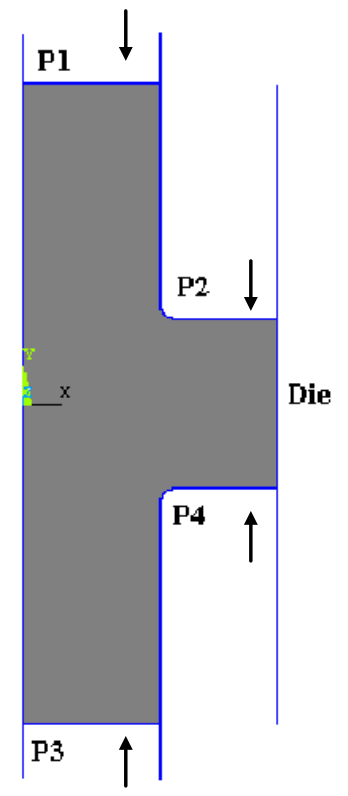

Figure 9: Powder and compation tools.

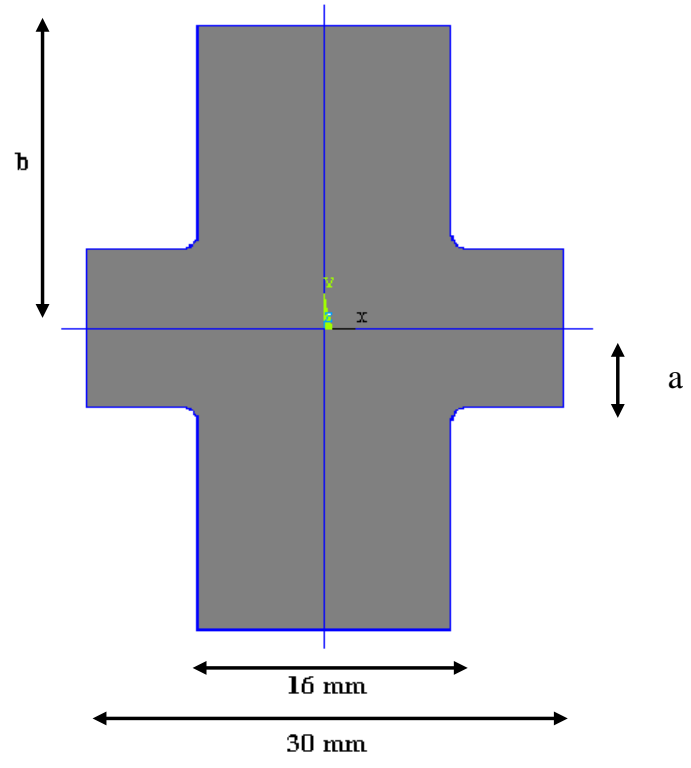

Fig. 8: Geometry of the part under study. $\mathrm{a}=5 \mathrm{~mm} ; \mathrm{b}=19 \mathrm{~mm}$.

gradients of density as a result of the filling stage. Actually, this feature is not yet known in detail and the simulation of the compression supposes an homogeneous initial distribution of density in the loose powder. The ejection of the compact is, also, a critical stage; spring-back in a such heterogeneous piece can produce its fracture. In the compaction of this part, four punches (Figure 9) act simultaneously. The kinematics presented in this work consists of moving these tools simultaneously but with different velocities and strokes. The objective is to produce a compact with an average final density of $6.8 \mathrm{Mg} / \mathrm{m}^{3}$ after ejection.

In the simulation presented here, a uniform initial density of $3.04 \mathrm{Mg} / \mathrm{m}^{3}$ have been supposed.

\subsection{The FEM Model}

The model consists of only a quarter of the total part due to the symmetries in the compaction stage. However, the ejection of the compact has been simulated with a half of the part because of the effect of friction. Tools have been considered to be rigid; then, only the powder and its behaviour have been studied, with the mesh presented in Figure 10. 


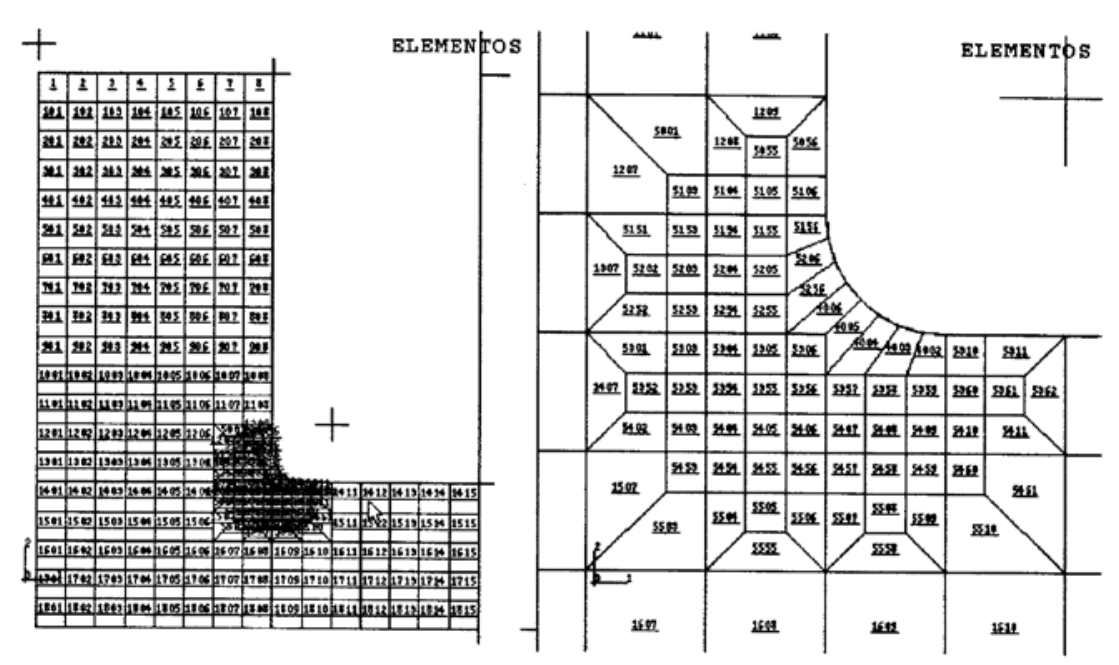

Figure 10: Mesh of the powder at the beginning of the compaction.
The Drucker-Prager/CAP model of Plasticity, presented previously, with the parameters already defined, has been implemented with the explicit version of the finite element code ABAQUS. The efficiency of an explicit integration is very high in cases such as that presented here: large deformations, contacts and complex constitutive equations.

Fig. 11 shows the void ratio distribution of the part at the beginning (left) and at the

end (right) of the compression stage. In general, the density is quite homogeneous over the entire piece, except, as it was expected, in the corner, where the densification level is clearly lower. Nevertheless, no cracks have been observed during the process.

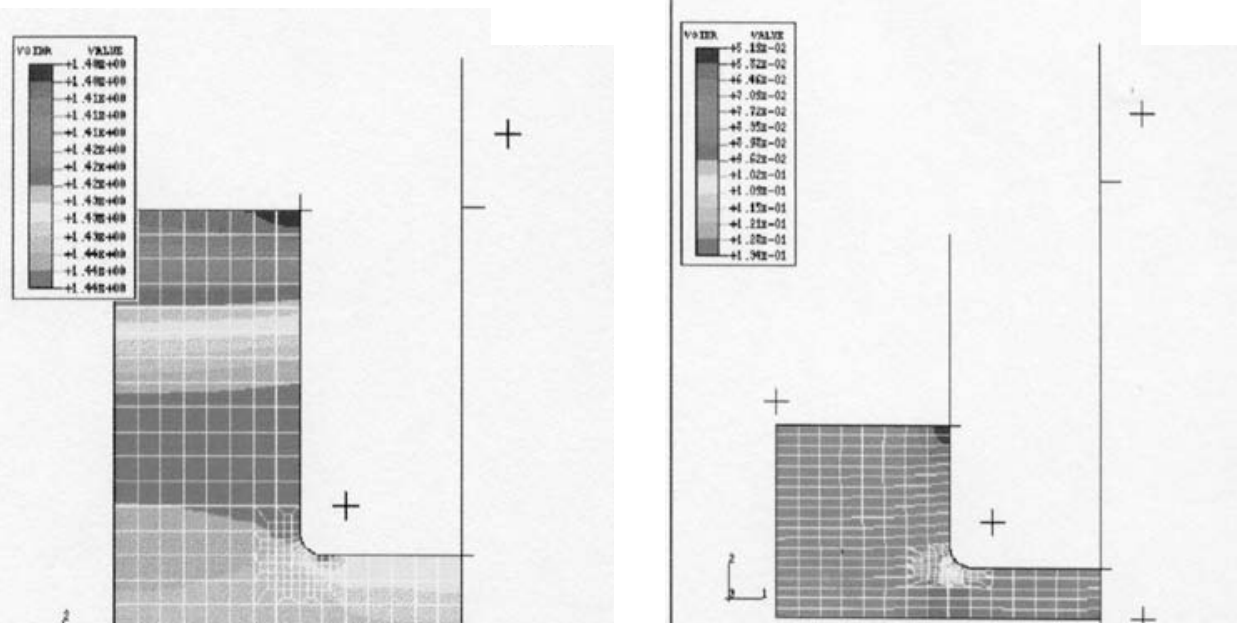

Fig. 11: Void ratio distribution before (left) and after (right) the compaction stage.
This situation constitutes the initial state in density for the ejection stage of the process. In fact, the complete mesh used to carry out the simulation of the ejection of the compact is, as it has been explained before, a half of the total part (Fig. 12).

The ejection of the aggregate has been

simulated by means of the implicit code of ABAQUS. The P1, P2 and P3 punches and the die are moved back progressively one after the other, and the compact becomes free. Fig. 13 represents the evolution in the material's flow with the movement of the tools during this process.

No cracks appear, but they are differences in density due to the non-uniform initial state; the regions more dense have more intensive elastic strain during the unloading stage; then, the final part has bigger gradients in density than after the compaction.

\section{CONCLUSIONS}

1. With the current knowledge about the mechanical behaviour of these materials, the DruckerPrager/CAP model of Plasticity represents rather well the response of the metallic powders to their compaction. There is an important lack in experimental data, especially in the region of failure. 

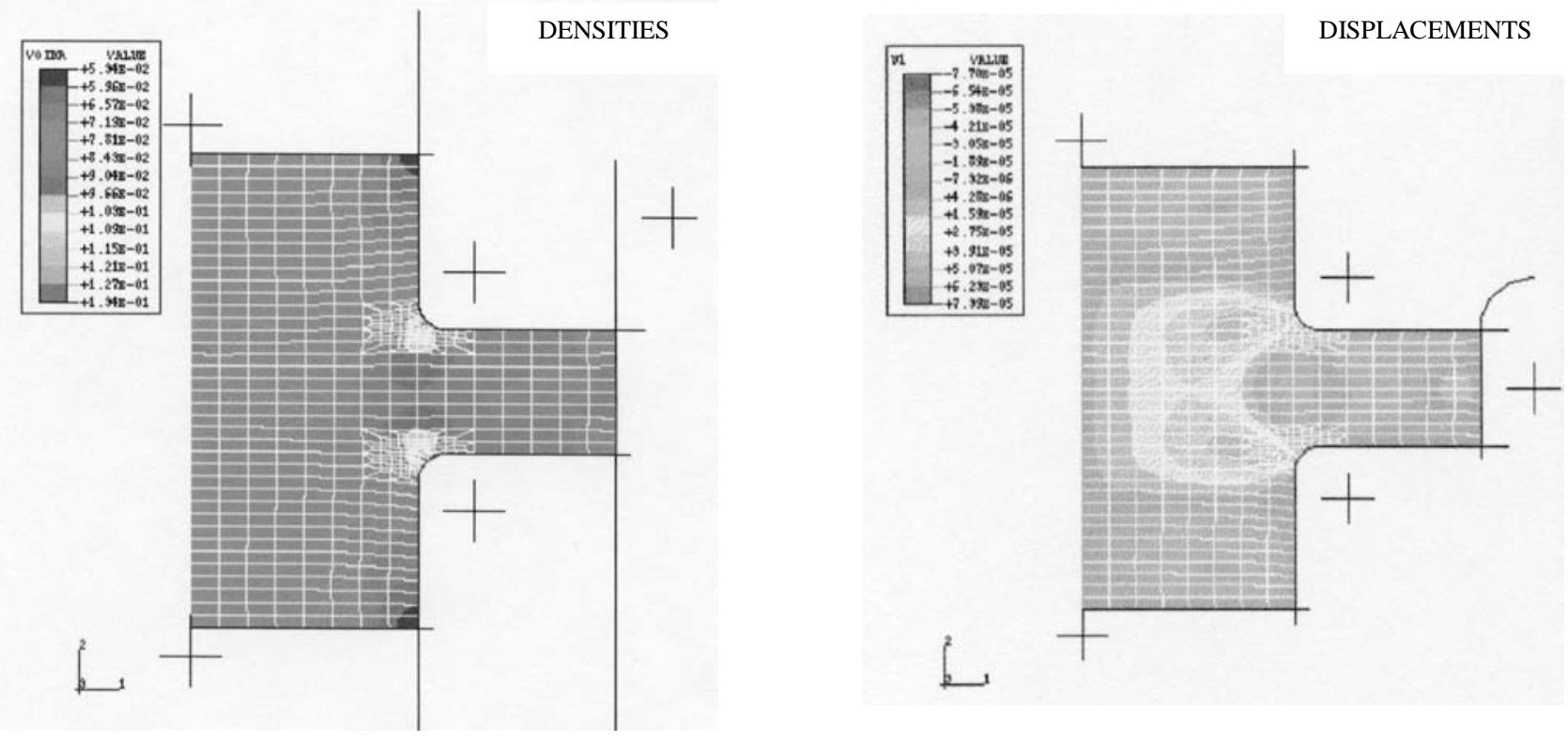

Fig. 12: Geometry, mesh, density (left) and displacement (right) distributions at the beginning of the ejection stage.
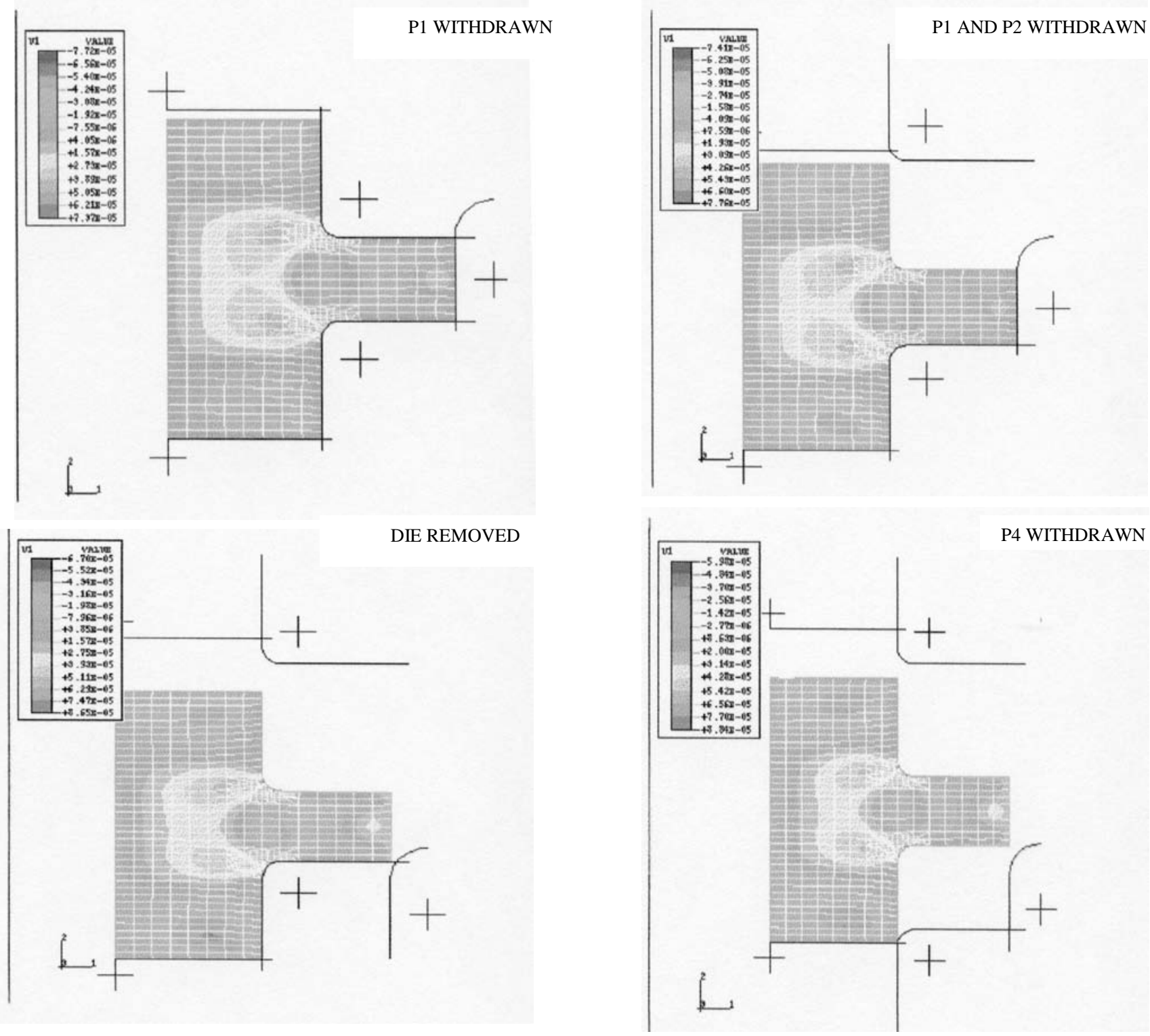

Fig. 13: Progressive spring-back during the ejection stage. 
2. The elasticity of the metallic compacts has been traditionally represented by means of a law relating stress and strain throughout a Young's modulus dependent on the density. But the results obtained testing samples, show new aspects that need to be incorporated into a better law. The elastic equation applied in this paper seems to be more appropriate to represent the spring-back during the ejection.

3. In this work the authors present the best process among many others also studied. The sequential and selective method to move back the tools improve the quality of the final part: its density distribution is more homogeneous and no cracks appear. Again, the use of simulation tools is a very efficient procedure to design components and processes. The possibility of combining explicit and implicit codes becomes a very useful tool in solving such non-linear problems.

\section{REFERENCES}

1. M. D. Riera. "Comportamiento elastoplástico de compactos Pulvimetalúrgicos”. Thesis. Universitat Politècnica de Catalunya. Barcelona. 1999.

2. D. C. Drucker and W. Prager. "Soil Mechanics and Plastic Analysis of Limit Design". Quarterly of Applied Mathematics. Vol. 10. 1952. Pp. 157-175.

3. C. S. Desai and H. J. Siriwardane. Constitutive Laws for Engineering Materials with emphasis on Geologic Materials. Ed. Prentice Hall, Inc. Englewood Cliffs, N. J. USA. 1984.

4. D. C. Drucker, R. E. Gibson and D. J. Henkel. "Soil Mechanics and Work Hardening Theories of Plasticity”. Proc. ASCE. Vol. 81. Paper 798. Set. 1955.

5. F. L. DiMaggio and F. L. DiMaggio. "Material Model for Granular Soils”. Journal of the Engineering Mechanics Division. ASCE. Vol. 97. N. EM3. Proc. Paper 8212. Jun. 1971. Pp. 935-950.

6. I. Sandler, F. L. DiMaggio and Y. Baladi. “Generalized Cap Model for Geological Materials”. Journal of Geotechnical Engineering Division. Vol. 102. N. GT7. 1976. Pp. 683-699.

7. M. D. Riera and J. M. Prado. "Uniaxial Compression Tests on Powder Metallurgical Compacts”. Proceedings of the 1998 Powder Metallurgy World Congress \& Exhibition. CDDocument number 615. Ed. EPMA. UK. 1998.

8. O. Coube. "Modelling and numerical Simulation of Powder Die Compaction with consideration of Cracking”. Thesis. Université Pierre et Marie Curie. Paris VI. 1998.

9. E. Pavier. "Caracterisation du comportement d'une poudre de fer pour le procedé de compression en matrice”. Thesis. Institut National Polytechnique de Grenoble. 1998.

10. Hibbitt, Karlsson and Sorensen, Inc. ABAQUS Theory Manual. Version 5.7. 1997.

11. J. M. Prado and M. D. Riera. "Modelling of Elastic Behaviour of Metal Powder Compacts". NATO Advanced Research Workshop. Recent Developments in Computer Modelling of Powder Metallurgy Processes. Series III: Computer and Systems Sciences-Vol. 176. ISSN: 1387-6694. Pp. 63-70. 2000.

12. M. D. Riera, J. M. Prado, A. Frachon, D. Imbault and P. Dorémus. "Modelling of Green Compact Elasticity”. Powder Metallurgy World Congress. PM'00. Kyoto (Japan). 2000. Proceedings. Vol. 1. ISBN 4-9900214-8-7. Pp. 598.

13. M. D. Riera, J. M. Prado and A. Larsson. "Determination of the green Strength of Powder Metallurgical Compacts by means of the Brazilian Test”. Powder Metallurgy World Congress. PM’00. Kyoto (Japan). 2000. Proceedings. Vol. 2. ISBN 4-9900214-8-7. Pp. 1617.

14. E. Pavier and P. Dorémus. "Comparison between constitutive equations modelling the compaction of iron powder and experimental data obtained with triaxial tests". Proceedings of the International Workshop on Modelling of Metal Powder Forming Processes. Grenoble (France). 1997. Pp. 1-17.

15. D. Fax. "Pulvertransfer und Scherrißbildung beim Pressen pulvermetallurgischer Formteile”. Diplomarbeit. Fakultät für Metallurgie und Werkstofftechnik der RWTH. (Germany). 1996. 
